\title{
Dynamic experimental investigation on the volatilization behavior of lead and cadmium in the simulated municipal solid waste (MSW) influenced by sulfur compounds during incineration
}

\author{
Changqi Liü, b, Yaji Huang ${ }^{\mathrm{a}, *}$, Xinye Wang ${ }^{\mathrm{a}}$, Shuaiyi Zhanga, Wenqing Xia ${ }^{\mathrm{a}}$, Chenggong Sun ${ }^{\mathrm{b}}$, \\ Hao Liu ${ }^{b^{*}}$
}

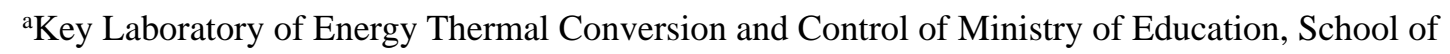
Energy and Environment, Southeast University, Nanjing 210096, China

${ }^{b}$ Faculty of Engineering, University of Nottingham, University Park, Nottingham NG7 2RD, UK

*Corresponding authors: heyyj@seu.edu.cn (Y. Huang), liu.hao@nottingham.ac.uk (H. Liu)

Abstract: In China, Coal, often with high level of sulfur, is always mixed with municipal solid waste (MSW) in waste incineration plants due to the low heating value and high moisture content of MSW. The influence of sulfur compounds on the volatilization of heavy metals in MSW is of great concern for China's waste incineration plants. In this study, the continuous dynamic volatilization process of $\mathrm{Pb}$ and $\mathrm{Cd}$ is investigated by adding different forms of sulfur compounds, elemental sulfur (S) and sodium sulfate $\left(\mathrm{Na}_{2} \mathrm{SO}_{4}\right)$, to the simulated MSW in a laboratory incinerator, both at $1 \mathrm{wt} \%$ and $3 \mathrm{wt} \%$, respectively. The experimental results show that the added $\mathrm{S}$ begins to affect the volatilization of $\mathrm{Pb}$ and $\mathrm{Cd}$ at about $700^{\circ} \mathrm{C}$; adding $\mathrm{S}$ can lead up to $49.6 \%$ reduction in the volatilization of $\mathrm{Pb}$ as the produced sulfur dioxide is promoting the formation of condensed sulfate phase, and part of $\mathrm{Pb}$ is fixed in the form of $\mathrm{PbS}$ in the bottom ash. But for $\mathrm{Cd}$, adding $\mathrm{S}$ causes up to $15.9 \%$ increase in its volatilization as $\mathrm{S}$ seizes part of $\mathrm{O}_{2}$ in the air, which is conducive to form the reducing atmosphere. In the reducing atmosphere, $\mathrm{CdO}$ can be easily reduced to $\mathrm{Cd}$ 
which volatilizes more easily than $\mathrm{CdO}$ at high temperatures. In fact, in the reducing atmosphere, the volatilization of $\mathrm{Cd}$ far outweighs the volatilization of $\mathrm{Pb}$ at $700^{\circ} \mathrm{C} \sim 800^{\circ} \mathrm{C}$. On the other hand, adding $\mathrm{Na}_{2} \mathrm{SO}_{4}$ almost has no influence on the volatilization of lead and cadmium below $900^{\circ} \mathrm{C}$.

Keyword: MSW incineration; Pb; Cd; Volatilization of heavy metals; Sulfur compounds

\section{Introduction}

With the development of urbanization and industrialization in China, there is a significant increase in the amount of municipal solid waste (MSW) generated annually. According to China's National Bureau of Statistics [1, 2], the amount of MSW generation in China increased from 155.09 million tons in 2004 to 178.60 million tons in 2014. In addition, the annual MSW generation in China is expected to reach over 480 million tons by 2030 [3]. MSW incineration has a number of advantages, especially comparing with landfilling, including considerable waste volume reduction, complete destruction of organic matter, energy recovery, and hence it now plays a significant role in China's MSW management and disposal practices, processing more than a quarter of the total MSW $[4,5]$. However, the emissions of fine particulates, heavy metals, trace dioxins and acid gases resulted from MSW incineration are causing major environmental and health concerns and therefore the control and mitigation of these emissions have received a lot of attentions over the recent years. The environmental regulations on the heavy metals emissions from MSW incineration plants in China are also expected to be more stringent in the near future $[3,6]$.

Heavy metals emissions are influenced by many factors including the waste composition such as the contents of chlorine $(\mathrm{Cl})$, sulfur $(\mathrm{S}), \mathrm{H}_{2} \mathrm{O}$, combustion temperature [7-9], and the composition of the gas stream such as $\mathrm{HCl}, \mathrm{SO}_{2}$ and $\mathrm{H}_{2} \mathrm{O}$ [10-13]. What's more, some sorbents in the furnace or in the flue gas can reduce the emissions of heavy metals $[14,15]$. Because of the low heating value 
and high moisture content of MSW, mixing MSW with some coal, especially high sulfur coals, is a common operational practice in China's MSW incineration plants. The sulfur in the coal is transformed to various forms of sulfur compounds during the combustion process which may impact on the heavy metals emissions of the MSW plant. There have been a number of previous studies focusing on the effects of sulfur compounds on heavy metals emissions from MSW incineration [9, 16-19]. For example, lead and cadmium partitioning in a simulated MSW incinerator was found to be influenced by the presence of sulfur compounds which contribute to fix cadmium in the bottom ash and prompt the lead into the fly ash [16]. The effect of sulfur on the volatilization of cadmium was found to be completely opposite in the oxidizing atmosphere to that in the reducing atmosphere as sulfur could stabilize cadmium in $\mathrm{CdS}$ in the reducing atmosphere while in the oxidizing atmosphere sulfur slightly enhanced the volatilization of $\mathrm{Cd}$ [17]. The results of thermodynamic equilibrium calculations showed that many heavy metals such as $\mathrm{Cd}, \mathrm{Zn}, \mathrm{Pb}$ and $\mathrm{Cu}$ could be immobilized in sulfate phases below $800^{\circ} \mathrm{C}$ [18]. The volatilization of $\mathrm{Pb}$ is both temperature dependent and fuel specific [19]. The influences of sulfur compounds on the volatilization and distribution of cadmium and lead were also investigated during sewage sludge incineration [20-22]. The effect of sulfur on the volatilization of $\mathrm{Cd}$ during sludge incineration was found to be the same as that of MSW incineration for both the reducing environment and the oxidizing environment [20, 21]. There are two steps in volatilizations of $\mathrm{Pb}$ and $\mathrm{Cd}$ : the first step of volatilizations are mainly controlled by the decomposition of their exchangeable, carbonate bound, iron-manganese bound fractions, and the second step of volatilizations originates from their complexed and residual fractions [22]. Almost all of these previous studies, however, have only focused on the effects of sulfur compounds on the partitioning of heavy metals in the incinerator, whereas the mechanisms 
responsible for the effects of sulfur compounds on the heavy metals emissions have not been fully explored.

This study is carried out to investigate the dynamic volatilizations of lead $(\mathrm{Pb})$ and cadmium (Cd) influenced by sulfur compounds during different periods of simulated MSW incineration. The mechanism of sulfur compounds' influence on the volatilizations of $\mathrm{Pb}$ and $\mathrm{Cd}$ is further investigated by thermal gravimetric analysis (TGA) and X-ray diffraction (XRD). The results of this study help to better understand the volatilization behaviors of $\mathrm{Pb}$ and $\mathrm{Cd}$ under the influence of sulfur compounds during MSW incineration and provide useful information for the development of effective heavy metal emission control strategies.

\section{Materials and methods}

\subsection{Dynamic experimental investigation on the volatilization of $\mathrm{Pb}$ and $\mathrm{Cd}$ during the}

\section{incineration of simulated MSW}

\subsubsection{Experimental samples}

Real MSW is inhomogeneous in nature due to its complexity and variability in composition, shapes and sizes and this makes it extremely difficult to obtain consistent results with gram-scale real MSW samples as used in this study. Therefore, simulated MSW samples are used in the experiment of this study so that stable waste components, controllable heavy metal components and uniform mixing can be ensured. Carbon particles are used to represent the combustible components of MSW, whereas $\mathrm{SiO}_{2}$ and $\mathrm{Al}_{2} \mathrm{O}_{3}$ powders are used to substitute the non-combustible components of MSW. Table 1 shows the components of the simulated MSW. $\mathrm{Pb}$ and $\mathrm{Cd}$ are added to the simulated MSW in the forms of $\mathrm{PbO}$ and $\mathrm{CdO}$ with the same concentration of $1500 \mathrm{mg} \mathrm{Pb} / \mathrm{kg}$ or $\mathrm{Cd} / \mathrm{kg}$ (dry weight). The contents of $\mathrm{PbO}$ and $\mathrm{CdO}$ used in the simulated waste represent the 
maximum levels of both heavy metals expected to be in real MSW. The use of the maximum levels of both heavy metals in the simulated MSW makes it easy to detect and more accurate to measure the volatilizations of heavy metals.

\subsubsection{Experimental apparatus}

The apparatus used in this study is showed in Fig.1, which mainly consists of the air supply device, a tube incinerator, a quartz-fiber filter and the absorption equipment.

The tube incinerator is made of a $1200 \mathrm{~mm}$ long horizontal quartz tube with $50 \mathrm{~mm}$ internal diameter. An alumina boat is placed at the center of the combustion chamber's 500mm long heating zone. The temperature of the electrically heated tubular furnace is controlled by a PID thermocontroller with a precision of $\pm 1 \square$. The heavy metals in the tail gas are captured by the glass fiber membrane which is fixed in position by the membrane filter clamp. Two bottles of dilute nitric acid absorption liquid (5\% v/v) in series are used to detect whether all of the released heavy metals are captured by the membrane filter.

\subsubsection{Experimental procedure}

The samples used in this study are listed in Table 2. After a sample is placed in the alumina boat, the boat is carefully pushed into the center of the combustion chamber. The air flow rate controlled by the flowmeter is maintained at $3 \mathrm{~L} / \mathrm{min}$. The temperature of the combustion chamber controlled by the thermocontroller rises from the room temperature to $900 \square$ with the heating rate of $10 \square / \mathrm{min}$, and stays at $900 \square$ for $60 \mathrm{~min}$. Starting from $300 \square$, the fly ash carried by the gas flow from the incinerator is collected by the glass fiber membrane filter as a sample for every $10 \mathrm{~min}$ until the temperature reaches $900^{\circ} \mathrm{C}$ and then a sample is collected for every $15 \mathrm{~min}$ when the temperature remains at $900{ }^{\circ} \mathrm{C}$. The heating of the furnace is terminated at the end of sampling and the alumina 
111

112

113

boat is withdrawn away from the high temperature zone for natural cooling. In order to continuously collect volatile heavy metals in different periods, when a sample is collected, the air supply to the combustion chamber is suspended, and a new set of membrane filter is replaced immediately before resuming the air supply with the whole process being completed in 5 seconds in order to minimize the escape of the volatized heavy metals. The inner side of the membrane filter clamp is cleaned by a solution of $5 \% \mathrm{HNO}_{3}$ after sampling, and then the cleaning solution and glass fiber membrane filters are digested in the same beaker. The residue in the alumina boat is also collected and is digested. For each of the dynamic experiments reported in this paper, at least three repeated runs have been completed.

\subsubsection{Detection of $\mathrm{Pb}$ and $\mathrm{Cd}$ concentrations and data analysis}

All samples collected in each period are digested in a solution of $10 \mathrm{ml} \mathrm{HCl}$ and $2.5 \mathrm{ml} \mathrm{HNO}$ at $95{ }^{\circ} \mathrm{C} \pm 5{ }^{\circ} \mathrm{C}$ without boiling for $8 \mathrm{~h}$ according to the modified U.S. EPA method 3050b [23]. Then, the acid solution is filtered with constant volume and analyzed by Atomic Absorption Spectroscopy (AAS) to detect the concentrations of $\mathrm{Pb}$ and $\mathrm{Cd}$.

The contents of heavy metals in the flue gas in this study are corrected using the content of heavy metals in the bottom ash remaining in the alumina boat after incineration. The correction takes account of the vaporized heavy metals lost to the walls of the furnace and pipes as well as during the periods of changing filters. The corrected mass of a heavy metal in the flue gas $\left(\mathrm{m}_{\mathrm{ir}}\right)$ in the $\mathrm{i}^{\text {th }}$ period is calculated by Equation (1):

$$
\mathbf{m}_{\mathbf{i r}}=\mathbf{m}_{\mathbf{i}} \times\left(\mathbf{m}_{\mathbf{a}}-\mathbf{m}_{\mathbf{b}}\right) / \sum_{\mathbf{i}=\mathbf{1}}^{\mathbf{n}} \mathbf{m}_{\mathbf{i}}
$$

$m_{i}$ indicates the weight of the heavy metal in the flue gas collected in the $i^{\text {th }}$ period; $m_{a}$ is the weight of the heavy metal in the simulated waste; $m_{b}$ is the weight of the heavy metal in the bottom 
133

ash; the average volatilization rate in the $\mathrm{i}^{\text {th }}$ period $\left(\mathrm{v}_{\mathrm{i}}\right)$ is calculated by Equation (2), the cumulative volatilization rate in the $\mathrm{i}^{\text {th }}$ period $\left(\mathrm{k}_{\mathrm{i}}\right)$ is calculated by Equation (3).

$$
\begin{aligned}
& \mathbf{v}_{\mathbf{i}}=\mathbf{m}_{\mathrm{ir}} /\left(\Delta \mathbf{t} \times \mathbf{m}_{\mathbf{a}}\right) \\
& \mathbf{k}_{\mathbf{i}}=\left(\sum_{\mathbf{i}=\mathbf{1}}^{\mathbf{n}} \mathbf{m}_{\mathrm{ir}}\right) / \mathbf{m}_{\mathbf{a}}
\end{aligned}
$$

\subsection{Flue gas analysis}

Concentrations of $\mathrm{CO}$ and $\mathrm{CO}_{2}$ in the flue gas are continuously analyzed by a gas analyzer (VARIOplus for Syngas-Analysis made by MRU Company in Germany) during the incineration of the simulated MSW. The results are used to confirm whether the volatilization of heavy metals occurs in the oxidizing or reducing atmosphere. This is especially important as previous studies have shown that the effect of sulfur on the volatilization of $\mathrm{Pb}$ and $\mathrm{Cd}$ in the reducing atmosphere is different from that in the oxidizing atmosphere [17].

\subsection{Thermal gravimetric analysis of $\mathrm{PbO}$ and $\mathrm{CdO}$}

In order to understand the characteristics of the related heavy metal oxides investigated by this study, the thermal gravimetric analyses of $\mathrm{PbO}$ and $\mathrm{CdO}$ are carried out with a NETZSCH STA 449C Thermogravimetric Analyzer. The weight losses (TG signals) of the samples are recorded continuously under non-isothermal conditions within the temperature range from room temperature to $1200{ }^{\circ} \mathrm{C}$ at a linear heating rate of $20^{\circ} \mathrm{C} / \mathrm{min}$. The original mass of each sample is kept at ca. 10mg, and the gas flow rates of the air and CO under two different conditions are fixed at 100 $\mathrm{ml} / \mathrm{min}$.

\subsection{Crystalline phase analysis}

In order to identify the crystalline phases and heavy metal speciation of the residue after the interactions between the heavy metals and the sulfur compounds, the heavy metal oxides and sulfur 
compounds are evenly mixed and placed in the alumina boat and incinerated in the tube furnace. The molar ratio of each heavy metal and sulfur $(\mathrm{S} / \mathrm{M})$ is fixed at 40 , which is similar to that used in the dynamic volatilization tests. Other experimental conditions including the air flow rate and the heating program are also consistent with those of the dynamic volatilization tests (Section 2.1.3). At the end of each test, the solid residue in the alumina boat is removed and turned into powder by mortar and pestle after cooling. The crystalline phases and heavy metal speciation of the residue in the alumina boat are then identified by the X-ray powder diffraction (XRD) analysis.

\section{Results and discussion}

\subsection{Effects of sulfur compounds on the volatilization of $\mathrm{Pb}$ and $\mathrm{Cd}$}

\subsubsection{Average volatilization rate}

As shown in Figure 2, the general trends for the average volatilization rates of $\mathrm{Pb}$ and $\mathrm{Cd}$ against the temperature do not change when the sulfur compounds are added to the simulated MSW. The average volatilization rates are small below $700^{\circ} \mathrm{C}$ but there are noticeable heavy metals volatilizations. After the temperature reaches $700^{\circ} \mathrm{C}$, the average volatilization rates of both $\mathrm{Pb}$ and $\mathrm{Cd}$ start to increase rapidly and reach the maximum during the $90^{\text {th }}-105^{\text {th }}$ min (with the temperature at $900^{\circ} \mathrm{C}$ ), and then decrease with time (with the temperature remaining at $900^{\circ} \mathrm{C}$ ). When no sulfur compounds are added to the simulated $\mathrm{MSW}, \mathrm{Pb}$ and $\mathrm{Cd}$ begin to volatize at $700^{\circ} \mathrm{C}$ to $800^{\circ} \mathrm{C}$, similar to the cases with sulfur compounds additions. When $\mathrm{S}$ is the added sulfur compound, the average volatilization rates of $\mathrm{Pb}$ in all periods are smaller than those with no sulfur addition (Figure 2(a)) after the temperature reaches $700^{\circ} \mathrm{C}$. On the other hand, after the addition of $\mathrm{S}$, the average volatilization rate of $\mathrm{Cd}$ has increased during the period of $70^{\text {th }}-105^{\text {th }}$ min when the temperature is in the range between $700^{\circ} \mathrm{C}$ and $900^{\circ} \mathrm{C}$ and then decreased for the remaining period (Figure 2(b)). 
177 When $\mathrm{Na}_{2} \mathrm{SO}_{4}$ is the sulfur compound added to the simulated MSW, however, the average

178 volatilization rates of $\mathrm{Pb}$ and $\mathrm{Cd}$ remain similar to those with no addition of sulfur compounds,

179 indicating $\mathrm{Na}_{2} \mathrm{SO}_{4}$ has little influence on the volatilizations of $\mathrm{Pb}$ or $\mathrm{Cd}$.

$180 \quad 3.1 .2$ Cumulative volatilization rate

181 The dynamic cumulative volatilization rates of $\mathrm{Pb}$ and $\mathrm{Cd}$ during the incineration process are shown in Fig. 3. Adding S to the simulated MSW leads to an obvious reduction in the cumulative volatilization rate of $\mathrm{Pb}$. From Figure 3(a), it can be seen that the cumulative volatilization rate of $\mathrm{Pb}$ has decreased from $23.0 \%$ to $13.5 \%$ and $11.6 \%$, respectively, with the additions of $1 \% \mathrm{~S}$ and $3 \%$ $\mathrm{S}$. The addition of a larger amount of S (1\% vs 3\%) has led to a greater reduction in the cumulative volatilization rate of $\mathrm{Pb}$. However, the additions of $1 \% \mathrm{Na}_{2} \mathrm{SO}_{4}$ and $3 \% \mathrm{Na}_{2} \mathrm{SO}_{4}$ have much smaller impact on the cumulative volatilization rate of $\mathrm{Pb}$ which is only slightly reduced to $21.5 \%$ and $21.9 \%$ respectively. These results indicate that $\mathrm{S}$ is better than $\mathrm{Na}_{2} \mathrm{SO}_{4}$ in inhibiting the volatilization of $\mathrm{Pb}$. Results shown in Fig.3 (b) confirm that different sulfur compounds also have different impacts on the volatilization rate of $\mathrm{Cd}$. Adding $\mathrm{S}$ promotes the volatilization of $\mathrm{Cd}$ with the volatilization rate of $\mathrm{Cd}$ increasing with the amount of $\mathrm{S}$ added, whereas adding $\mathrm{Na}_{2} \mathrm{SO}_{4}$ has little influence on the cumulative volatilization rate of $\mathrm{Cd}$.

3.2 Analysis on the influence mechanisms of the added sulfur compounds on the volatilizations of $\mathrm{Pb}$ and $\mathrm{Cd}$ during the incineration of the simulated MSW

\subsubsection{Concentrations of $\mathrm{CO}$ and $\mathrm{CO}_{2}$ in flue gas}

Figure 4 shows the concentration profiles of $\mathrm{CO}$ and $\mathrm{CO}_{2}$ in the flue gas during the incineration process of the simulated MSW. The simulated MSW begins to burn and release $\mathrm{CO}_{2}$ at about $400^{\circ} \mathrm{C}$ (Figure 4(a)). The concentration of $\mathrm{CO}_{2}$ in the flue gas reaches the maximum level at about $600^{\circ} \mathrm{C}$, 
stays at the high level until about $750^{\circ} \mathrm{C}$, reduces gradually when the temperature is increased to $900^{\circ} \mathrm{C}$ and then is further decreased to less than $1 \%$ after the temperature remaining at $900^{\circ} \mathrm{C}$ for 20mins, which indicates the end of the simulated MSW combustion. Figure 4(b) shows that CO begins to appear in the flue gas at about $460^{\circ} \mathrm{C}$ and its concentration increases rapidly after this point. The concentration of $\mathrm{CO}$ reaches the maximum value of about $5800 \mathrm{ppm}$ at about $550^{\circ} \mathrm{C}$, stays at this value until the temperature is about $610^{\circ} \mathrm{C}$ and then decreases rapidly to almost zero ppm at $740^{\circ} \mathrm{C}$. The concentration profiles of $\mathrm{CO}$ and $\mathrm{CO}_{2}$ in the flue gas shown in Figure 4 indicate that the simulated MSW undergoes pyrolysis, gasification and combustion reactions and experiences both reducing and oxidizing atmospheres during the incineration process in the tube furnace. When the pyrolysis and gasification reactions are fast, more $\mathrm{CO}$ is generated than it can be burned by the combustion reactions, hence resulting in the simulated MSW experiencing a period of a reducing atmosphere in the tube furnace. At the later stage of the incineration (after $75^{\text {th }} \mathrm{min}$ ), there is no CO detected in the flue gas (Figure 4(b)), indicating the simulated MSW is further incinerated under oxidizing conditions.

\subsubsection{Thermal gravimetric characteristics of $\mathrm{PbO}$ and $\mathrm{CdO}$}

In order to understand the thermal gravimetric characteristics of $\mathrm{PbO}$ and $\mathrm{CdO}$ under oxidizing and reducing conditions, TGA analyses of $\mathrm{PbO}$ and $\mathrm{CdO}$ have been carried out in the atmospheres of air and CO, respectively and the results are presented in Figure 5. Figure 5(a) shows the weight loss of $\mathrm{PbO}$ in the gas flow of air begins at about $900^{\circ} \mathrm{C}$, whereas in the gas flow of $\mathrm{CO}$, it begins at about $300^{\circ} \mathrm{C}$. Similarly, Figure 5 (b) shows the weight loss of $\mathrm{CdO}$ does not begin until the temperature reaches about $1000^{\circ} \mathrm{C}$ in the gas flow of air, however, in the gas flow of $\mathrm{CO}$, the weight loss of $\mathrm{CdO}$ begins at a much lower temperature, about $300^{\circ} \mathrm{C}$. These results indicate there is no 
221

222

223

volatilization of $\mathrm{PbO}$ and $\mathrm{CdO}$ before $900^{\circ} \mathrm{C}$ under the oxidizing condition. However, there are significant weight losses for both $\mathrm{PbO}$ and $\mathrm{CdO}$ before $900^{\circ} \mathrm{C}$ under the reducing condition. Under the reducing condition, both $\mathrm{PbO}$ and $\mathrm{CdO}$ can react with $\mathrm{CO}$ to generate $\mathrm{CO}_{2}$ and the elemental heavy metals according to (R1-R2). The generated $\mathrm{CO}_{2}$ and the subsequent volatilizations of $\mathrm{Pb}$ and Cd lead to the observed reductions in the remaining sample weights before $900^{\circ} \mathrm{C}$ (Figure 5(a)-(b)). Comparing Figure 5(a) with Figure 5(b), it can be seen that $\mathrm{CdO}$ is reduced more easily than $\mathrm{PbO}$ under the same reducing condition. At $900^{\circ} \mathrm{C}$, more than $97 \%$ of $\mathrm{CdO}$ has been lost whereas the weight loss of $\mathrm{PbO}$ is less than $14 \%$.

$$
\begin{aligned}
& \mathrm{PbO}+\mathrm{CO} \rightarrow \mathrm{Pb}+\mathrm{CO}_{2} \\
& \mathrm{CdO}+\mathrm{CO} \rightarrow \mathrm{Cd}+\mathrm{CO}_{2}
\end{aligned}
$$

\subsubsection{XRD analysis}

The crystalline phases and heavy metal speciation of the residue in the alumina boat after the interactions between the heavy metal oxides and the sulfur compounds (Section 2.4) are identified by the X-ray powder diffraction (XRD) analysis. As shown in Figure 6 (a), for the mixture of $\mathrm{PbO}$ and $\mathrm{S}$ at $700^{\circ} \mathrm{C}$, the bottom residue contains $\mathrm{PbS}, \mathrm{PbSO}_{4}$ and $\mathrm{PbO}$ and this indicates that some $\mathrm{PbO}$ has reacted with $\mathrm{S}$ and $\mathrm{O}_{2}$ to generate $\mathrm{PbS}$ and $\mathrm{PbSO}_{4}$. At $800^{\circ} \mathrm{C}, \mathrm{PbO}$ is no longer in the bottom residue and only $\mathrm{PbS}$ and $\mathrm{Pb}_{2}\left(\mathrm{SO}_{4}\right) \mathrm{O}$ can be found (Fig.6 (a)). This indicates that when the temperature reaches $800^{\circ} \mathrm{C}$, all $\mathrm{PbO}$ has reacted with $\mathrm{S}$ and $\mathrm{O}_{2}$ to generate $\mathrm{PbS}$ and $\mathrm{PbSO}_{4}$ and all $\mathrm{Pb}$ is fixed in the bottom residue in the form of $\mathrm{PbS}$ and condensed sulfate phase. Figure 6(b) shows that at $700^{\circ} \mathrm{C}$ some $\mathrm{CdO}$ has reacted with $\mathrm{S}$ and $\mathrm{O}_{2}$ to generate $\mathrm{CdS}$ and $\mathrm{Cd}_{3} \mathrm{O}_{2} \mathrm{SO}_{4}$ but at $800^{\circ} \mathrm{C}$ the bottom residue only contains a large amount of $\mathrm{CdO}$ (both larger diffraction peak intensity and peak area) and a small amount of $\mathrm{CdS}$. This indicates at $800^{\circ} \mathrm{C} \mathrm{Cd}$ is largely remaining in the bottom 
residue in the form of $\mathrm{CdO}$, rather than is fixed as $\mathrm{CdS}$ in the bottom residue, contrasting to what is observed with $\mathrm{Pb}$ in Figure 6(a). Results in Figure 6 (c) and 6 (d) show that $\mathrm{PbO}$ and $\mathrm{CdO}$ do not react with $\mathrm{Na}_{2} \mathrm{SO}_{4}$ even the temperature reaches $900^{\circ} \mathrm{C}$, indicating that adding $\mathrm{Na}_{2} \mathrm{SO}_{4}$ to $\mathrm{MSW}$ will have little influence on the volatilization of lead and cadmium below $900^{\circ} \mathrm{C}$.

\subsubsection{Discussion on the influence mechanisms of the added sulfur compounds on the} volatilizations of $\mathrm{Pb}$ and $\mathrm{Cd}$ during the simulated MSW incineration

The experimental results and analysis described in the above subsections (Subsections 3.2.1 3.2.3) can be used to deduce the influence mechanisms of sulfur compounds on the volatilizations of $\mathrm{Pb}$ and $\mathrm{Cd}$ during the incineration of the simulated MSW (Section 3.1). Adding $\mathrm{S}$ inhibits the volatilization of $\mathrm{Pb}$ from the incineration of the simulated MSW (Figure 2(a) and Figure 3(a)) and this is partly due to fact that the oxygen in the air combines with sulfur to produce sulfur dioxide which is propitious to the formation of condensed sulfate phase [19, 21, 24]. The presence of $\mathrm{S}$ also leads to $\mathrm{Pb}$ fixation in the form of $\mathrm{PbS}$ which will more likely stay in the bottom residue as the melting point and boiling point of $\mathrm{PbS}$ are higher than those of heavy metal oxides and sulfates and the vapor pressure of $\mathrm{PbS}$ is lower than that of heavy metal oxides and sulfates $[16,17,20,25]$.

The reasons for the promotional influence of the added $\mathrm{S}$ on the volatilization of $\mathrm{Cd}$ during the incineration of the simulated MSW (Figure 2(b) and Figure 3(b)) can be deduced as follows: S start to burn in air at about $300^{\circ} \mathrm{C}$, but $\mathrm{CO}$ appears in the incinerator at about $460^{\circ} \mathrm{C}$; therefore, oxygen in the air combines with sulfur to produce sulfur dioxide firstly; the reduced oxygen available for the incineration of the simulated MSW leads to more CO in the tube furnace comparing with the case without the addition of S. Figure 5 has already showed that at $900^{\circ} \mathrm{C}$, in the gas flow of $\mathrm{CO}$ the weight loss of $\mathrm{CdO}$ is more than $97 \%$, while the weight loss of $\mathrm{PbO}$ is less than $14 \%$. The large 
difference of the weight loss between $\mathrm{CdO}$ and $\mathrm{PbO}$ indicates that the volatilization of $\mathrm{Cd}$ far outweighs the volatilization of $\mathrm{Pb}$ in the reducing atmosphere and this is one of the reasons why $\mathrm{S}$ promotes the volatilization of $\mathrm{Cd}$ but inhibits the volatilization of $\mathrm{Pb}$ in the dynamic tests shown in Figures 2-3. In addition, $\mathrm{CdO}$ can be reduced by $\mathrm{CO}$ according to $\mathrm{R} 2$ to $\mathrm{Cd}$ which has much lower melting point and boiling point than those of $\mathrm{CdO}$, and this also leads to more volatilization of $\mathrm{Cd}$ from the simulated MSW.

Figures 6 (c) and (d) have already showed that $\mathrm{Na}_{2} \mathrm{SO}_{4}$ does not react with $\mathrm{PbO}$ and $\mathrm{CdO}$ even at $900^{\circ} \mathrm{C}$ and therefore, adding $\mathrm{Na}_{2} \mathrm{SO}_{4}$ to the simulated MSW should have no influence on the volatilization of the heavy metals (lead and cadmium) in the simulated MSW. However, as the $\mathrm{Na}_{2} \mathrm{SO}_{4}$ in the incineration system can absorb heat when being melted, which can slightly inhibit the volatilizations of $\mathrm{Pb}$ and $\mathrm{Cd}$ as shown in Figures 2-3.

\section{Conclusions}

The dynamic volatilization processes of $\mathrm{Pb}$ and $\mathrm{Cd}$ during the simulated MSW incineration with and without the addition of sulfur compounds ( $\mathrm{S}$ and $\left.\mathrm{Na}_{2} \mathrm{SO}_{4}\right)$ have been investigated with a tube furnace. Adding sulfur compounds to the simulated MSW have no effect on the volatilizations of $\mathrm{Pb}$ and $\mathrm{Cd}$ below $700^{\circ} \mathrm{C}$ but the influences increase with temperature once it is above $700^{\circ} \mathrm{C}$. Adding elemental $\mathrm{S}$ to the simulated MSW inhibits the volatilization of $\mathrm{Pb}$ but also promotes the volatilization of $\mathrm{Cd}$. On the other hand, adding $\mathrm{Na}_{2} \mathrm{SO}_{4}$ to the simulated MSW has little influence on the volatilization behaviors of $\mathrm{Pb}$ and $\mathrm{Cd}$ during the incineration process.

In order to elucidate the influence mechanisms of the added sulfur compounds on the volatilizations of heavy metals $(\mathrm{Pb}$ and $\mathrm{Cd})$ during the incineration process, additional tests have been carried out. Considering the existence of both oxidizing and reducing atmospheres during the 
incineration process of the simulated MSW, the TGA tests of $\mathrm{PbO}$ and $\mathrm{CdO}$ have been carried out under both oxidizing (in the gas flow of air) and reducing (in the gas flow of CO) conditions. The interactions between the heavy metal oxides and the sulfur compounds have also been studied by using the same tube furnace and the same temperature-programmed incineration process as the dynamic volatilization tests of the simulated MSW and XRD analyses have been carried to identify heavy metal species left in the solid residue.

These additional experimental results indicate the added $\mathrm{S}$ affects the volatilizations of $\mathrm{Pb}$ and $\mathrm{Cd}$ in the simulated MSW during incineration through different mechanisms. For $\mathrm{Pb}$, it is mostly fixed in the bottom residue in the form of $\mathrm{PbS}$ and condensed sulfate phase and hence the added $\mathrm{S}$ inhibits the volatilization of $\mathrm{Pb}$ during the incineration process. For $\mathrm{Cd}$, only a small amount of $\mathrm{Cd}$ is fixed in the form of CdS in the bottom residue and hence it is either released in the vapor phase or remains in the original form of $\mathrm{CdO}$ in the bottom residue. As $\mathrm{CdO}$ can be reduced to $\mathrm{Cd}$ in the reducing atmosphere experienced by the $\mathrm{MSW}$ at $700^{\circ} \mathrm{C} \sim 800^{\circ} \mathrm{C}$ and the volatilization of $\mathrm{Cd}$ occurs more easily than $\mathrm{CdO}$, the added $\mathrm{S}$ thus promotes the volatilization of $\mathrm{Cd}$ during the incineration process, contrasting to the volatilization of $\mathrm{Pb}$ which is inhibited by the added $\mathrm{S}$.

\section{Acknowledgements}

The authors gratefully acknowledge the support from the National Natural Science Foundation of China (No. 51476031) and the Doctoral Fund of Ministry of Education of China (No.20130092110007). The authors would also like to acknowledge the provision of a scholarship to Mr Changqi Liu by the China Scholarship Council (CSC) which enables him to be able to complete part of the reported work at the University of Nottingham.

\section{References}


309

310

311

312

313

314

315

316

317

318

319

320

321

322

323

324

325

[1] Chinese Statistics Yearbook Compiling Committee. Chinese statistics yearbook 2004; Chinese Statistics Press: Beijing, 2004.

[2] Chinese Statistics Yearbook Compiling Committee. Chinese statistics yearbook 2014; Chinese Statistics Press: Beijing, 2014.

[3] Yu, J.; Sun, L.; Xiang, J.; Hu, S.; Su, S.; Qiu, J., Vaporization of heavy metals during thermal treatment of model solid waste in a fluidized bed incinerator. Chemosphere 2012, 86, (11), 11221126.

[4] Dong, J.; Chi, Y.; Tang, Y.; Ni, M.; Nzihou, A.; Weiss-Hortala, E.; Huang, Q., Partitioning of Heavy Metals in Municipal Solid Waste Pyrolysis, Gasification, and Incineration. Energy \& Fuels 2015, 29, (11), 7516-7525.

[5] Ji, L.; Lu, S.; Yang, J.; Du, C.; Chen, Z.; Buekens, A.; Yan, J., Municipal solid waste incineration in China and the issue of acidification: A review. Waste Management \& Research 2016, 34, (4), 280-297.

[6] Hu, H.; Liu, H.; Shen, W.; Luo, G.; Li, A.; Lu, Z.; Yao, H., Comparison of CaO’s effect on the fate of heavy metals during thermal treatment of two typical types of MSWI fly ashes in China. Chemosphere 2013, 93, (4), 590-596.

[7] Rio, S.; Verwilghen, C.; Ramaroson, J.; Nzihou, A.; Sharrock, P., Heavy metal vaporization and abatement during thermal treatment of modified wastes. Journal of Hazardous Materials 2007, 148, (3), 521-528.

[8] Morf L S, Brunner P H, Spaun S. Effect of operating conditions and input variations on the partitioning of metals in a municipal solid waste incinerator. Waste Management and Research, 2000 , $18,(1), 4-15$. 
331

[9] Zhang, Y.; Meng, H.; Chen, Y.; Zhou, Q.; Chen H., Effects of Sulfur Compounds on Cd Partitioning in a Simulated Municipal Solid Waste Incinerator. Chinese Journal of Chemical Engineering 2007, 15, (6), 889-894.

[10] Zhang Y, Li Q, Jia J, et al. Thermodynamic analysis on heavy metals partitioning impacted by moisture during the MSW incineration. Waste management, 2012, 32(12): 2278-2286.

[11] Li Q, Meng A, Jia J, et al. Investigation of heavy metal partitioning influenced by flue gas moisture and chlorine content during waste incineration. Journal of Environmental Sciences, 2010, 22, (5), 760-768.

[12] Jiao F, Zhang L, Yamada N, et al. Effect of $\mathrm{HCl}, \mathrm{SO}_{2}$ and $\mathrm{H}_{2} \mathrm{O}$ on the condensation of heavy metal vapors in flue gas cooling section. Fuel processing technology, 2013, 105, 181-187.

[13] Jiao F, Cheng Y, Zhang L, et al. Effects of $\mathrm{HCl}$, SO 2 and $\mathrm{H} 2 \mathrm{O}$ in flue gas on the condensation behavior of $\mathrm{Pb}$ and $\mathrm{Cd}$ vapors in the cooling section of municipal solid waste incineration. Proceedings of the Combustion Institute, 2011, 33, (2), 2787-2793.

[14] Tang Y T, Ma X Q, Zhang C, et al. Effects of sorbents on the heavy metals control during tire rubber and polyethylene combustion in $\mathrm{CO}_{2} / \mathrm{O}_{2}$ and $\mathrm{N}_{2} / \mathrm{O}_{2}$ atmospheres. Fuel, 2016, 165, 272-278.

[15] Ma L, Mao Y, JiantaoChen H Z. Removal of Cd-Pb-Hg Heavy Metal Ion from Simulation MSW Incineration Flue Gas by Modified Mineral Adsorbents. Frontier of Environmental Science, 2014, 3, (3), 109-118.

[16] Chen, Y.; Zhang, Y.; Li, H.; Zhou, Q.; Chen H., Effects of sulfur compounds on Cd and Pb partitioning in a simulated MSW incinerator. J Tsingh ua Univ ( Sci \& Tech ) 2008, 48, (2), 232235. (In Chinese)

[17] Zhang, Y.; Chen, Y.; Meng, A.; Li, Q.; Cheng, H., Experimental and thermodynamic 
353

354

355

356

357

358

359

360

361

362

363

364

365

366

367

368

369

370

371

372

373

investigation on transfer of cadmium influenced by sulfur and chlorine during municipal solid waste (MSW) incineration. Journal of Hazardous Materials 2008, 153, (1-2), 309-319.

[18] Verhulst, D.; Buekens, A., Thermodynamic Behavior of Metal Chlorides and Sulfates under the Conditions of Incineration Furnaces. Environ. Sci. Technol 1996, 30, (1), 50-56.

[19] Pedersen A J, Van Lith S C, Frandsen F J, et al. Release to the gas phase of metals, S and Cl during combustion of dedicated waste fractions. Fuel Processing Technology, 2010, 91, (9), 10621072.

[20] Liu, J.; Fu, J.; Sun, S.; Ning, X.; Wang, Y.; Chen, T.; Luo, G.; Xie, W.; Yang, Z.; Zhuo, Z., Effect of different sulfides on cadmium distribution during sludge combustion based on experimental and thermodynamic calculation approaches. Environmental Science and Pollution Research 2015, 22, (2), 1113-1126.

[21] Luan, J.; Li, R.; Zhang, Z.; Li, Y.; Zhao, Y., Influence of chlorine, sulfur and phosphorus on the volatilization behavior of heavy metals during sewage sludge thermal treatment. Waste Management \& Research 2013, 31, (10), 1012-1018.

[22] Luan, J.; Li, R.; Zhang, Z.; Li, Y.; Zhao, Y., Speciation evolutions of target metals (Cd, Pb) influenced by chlorine and sulfur during sewage sludge incineration. Frontiers of Environmental Science \& Engineering 2014, 8, (6), 871-876.

[23] Wang X, Huang Y, Zhong Z, et al. Control of inhalable particulate lead emission from incinerator using kaolin in two addition modes. Fuel Processing Technology, 2014, 119, 228-235.

[24] Mkilaha, I.; Yao, H.; Naruse, I., Thermodynamic analysis of the role of chlorine and sulfur environments during combustion and incineration processes. Journal of Material Cycles \&amp; Waste Management 2002, 4, 143-149. 
375

376

377

378

379

380

381

382

383

384

385

386

387

388

389

390

391

392

393

394

395

396

397

398

399

400

401

402

[25] Wu, F.; Su, Y.; Wang, H.; Hu, H.; Zhao, Q., Effect of atmospheres on transfer characteristic of heavy metals during municipal solid waste incineration process. Chinese Journal of Environmental

Engineering, 2011, 5, (07), 1623-1626.

.

(1)

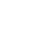

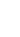

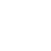

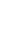


Table 2 Components of the samples

\begin{tabular}{cc}
\hline Notations of the Samples & Composition of the samples \\
\hline No sulfur & $15.0489 \mathrm{~g}$ simulated MSW \\
$1 \% \mathrm{~S}$ & $15.0489 \mathrm{~g}$ simulated MSW and 0.152g S \\
$3 \% \mathrm{~S}$ & $15.0489 \mathrm{~g}$ simulated MSW and 0.465g S \\
$1 \% \mathrm{Na}_{2} \mathrm{SO}_{4}$ & $15.0489 \mathrm{~g}$ simulated MSW and $0.675 \mathrm{ga}_{2} \mathrm{SO}_{4}$ \\
$3 \% \mathrm{Na}_{2} \mathrm{SO}_{4}$ & $15.0489 \mathrm{~g}$ simulated MSW and 2.995g Na $\mathrm{SO}_{4}$ \\
\hline
\end{tabular}

440

441

442

443

444

445

446 
Fig. 1 Schematic diagram of the laboratory incinerator 1-Diaphragm pump, 2- flowmeter, 3- Quartz tube, 4- Tube incinerator, 5- Thermocontroller, 
494

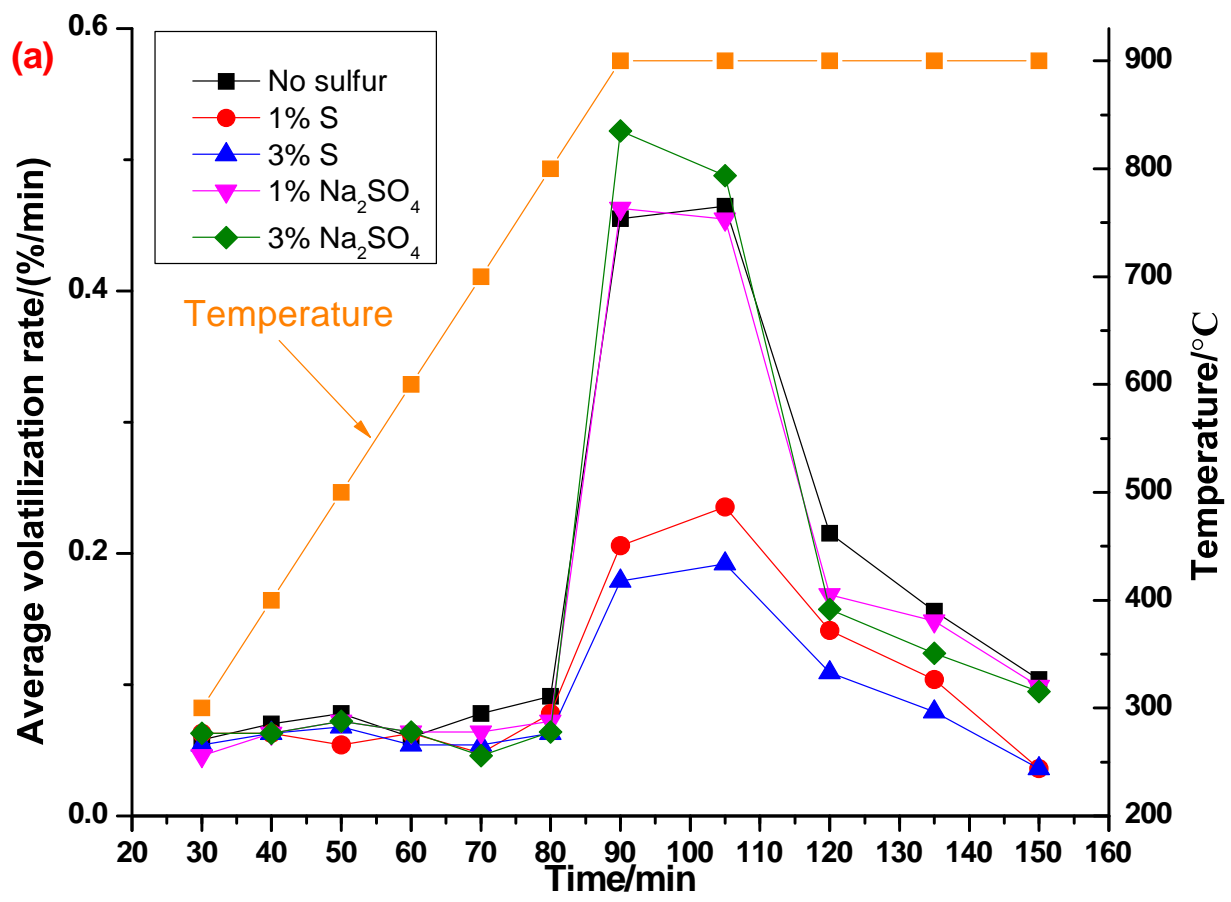


499

500

501

502

503

504

505

506

507

508

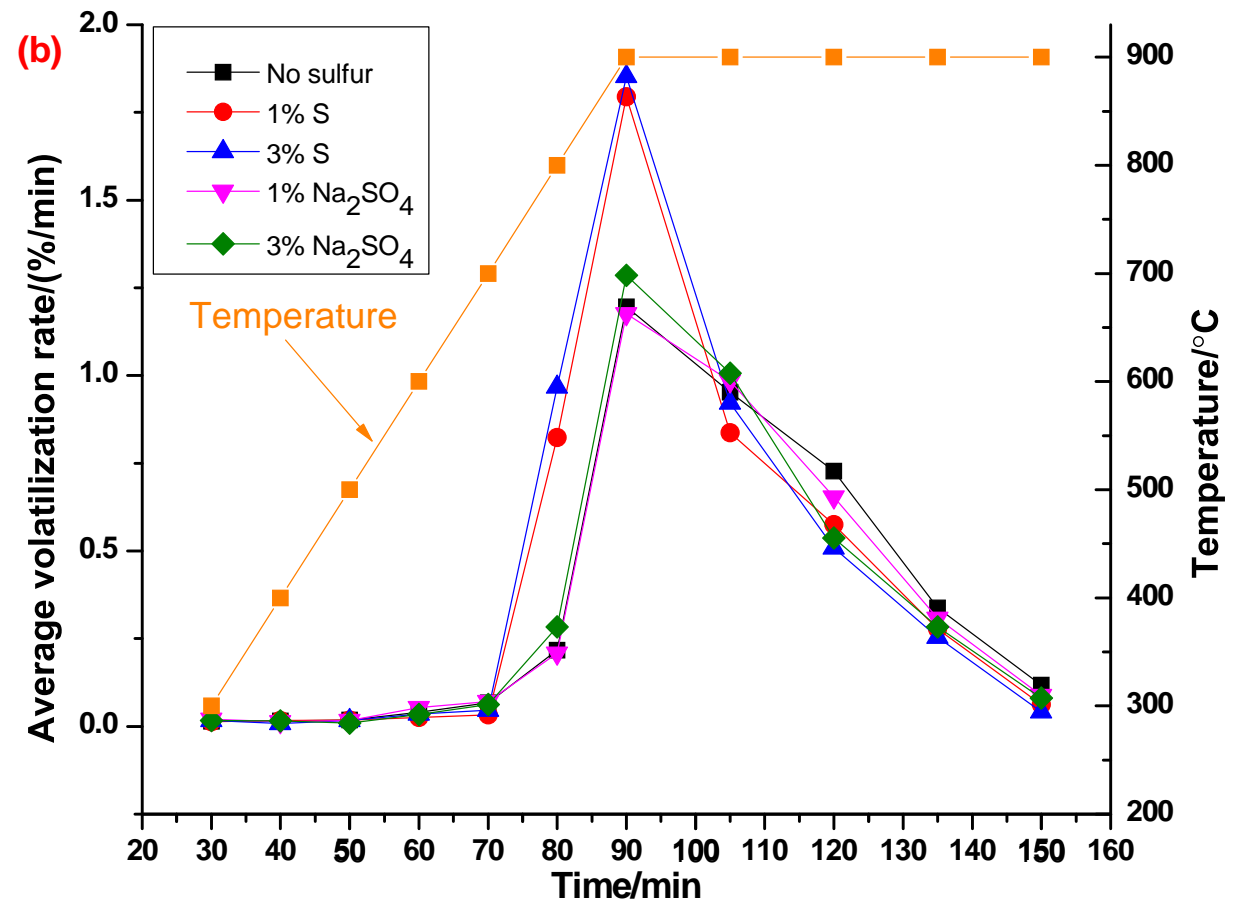

Fig. 2 Effects of sulfur compounds on the average volatilization rates of $\mathrm{Pb}(\mathrm{a})$ and $\mathrm{Cd}(\mathrm{b})$ 

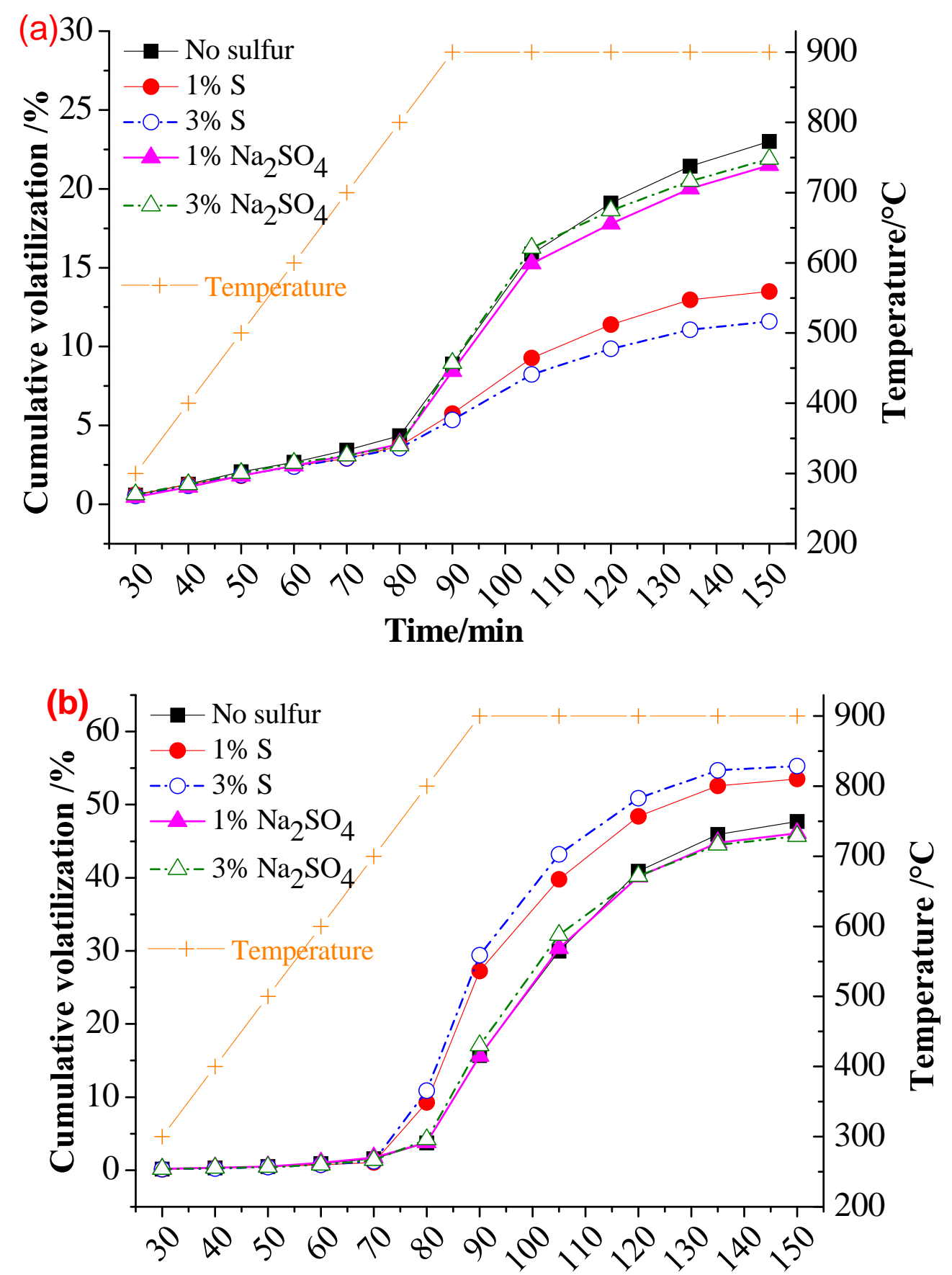

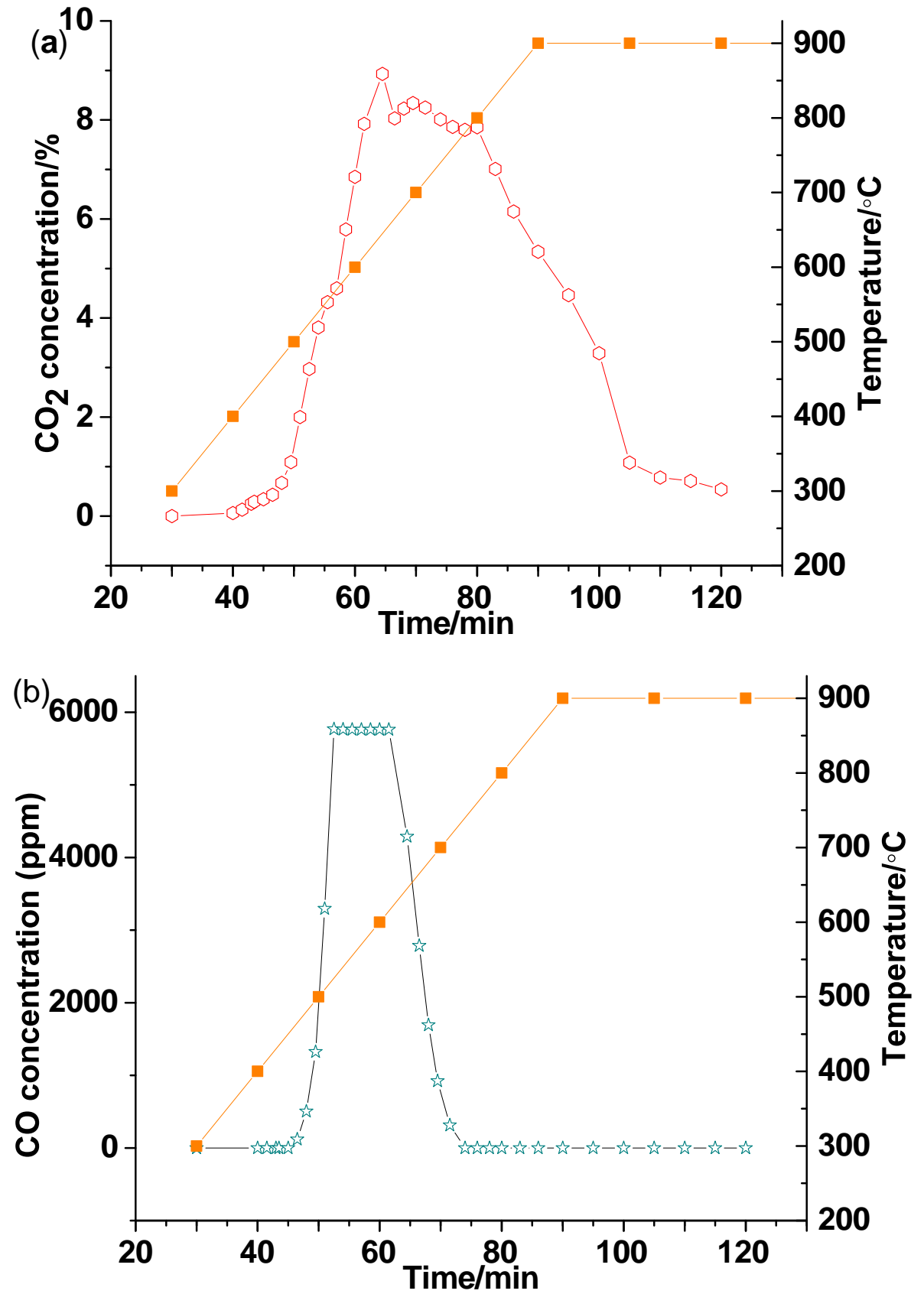

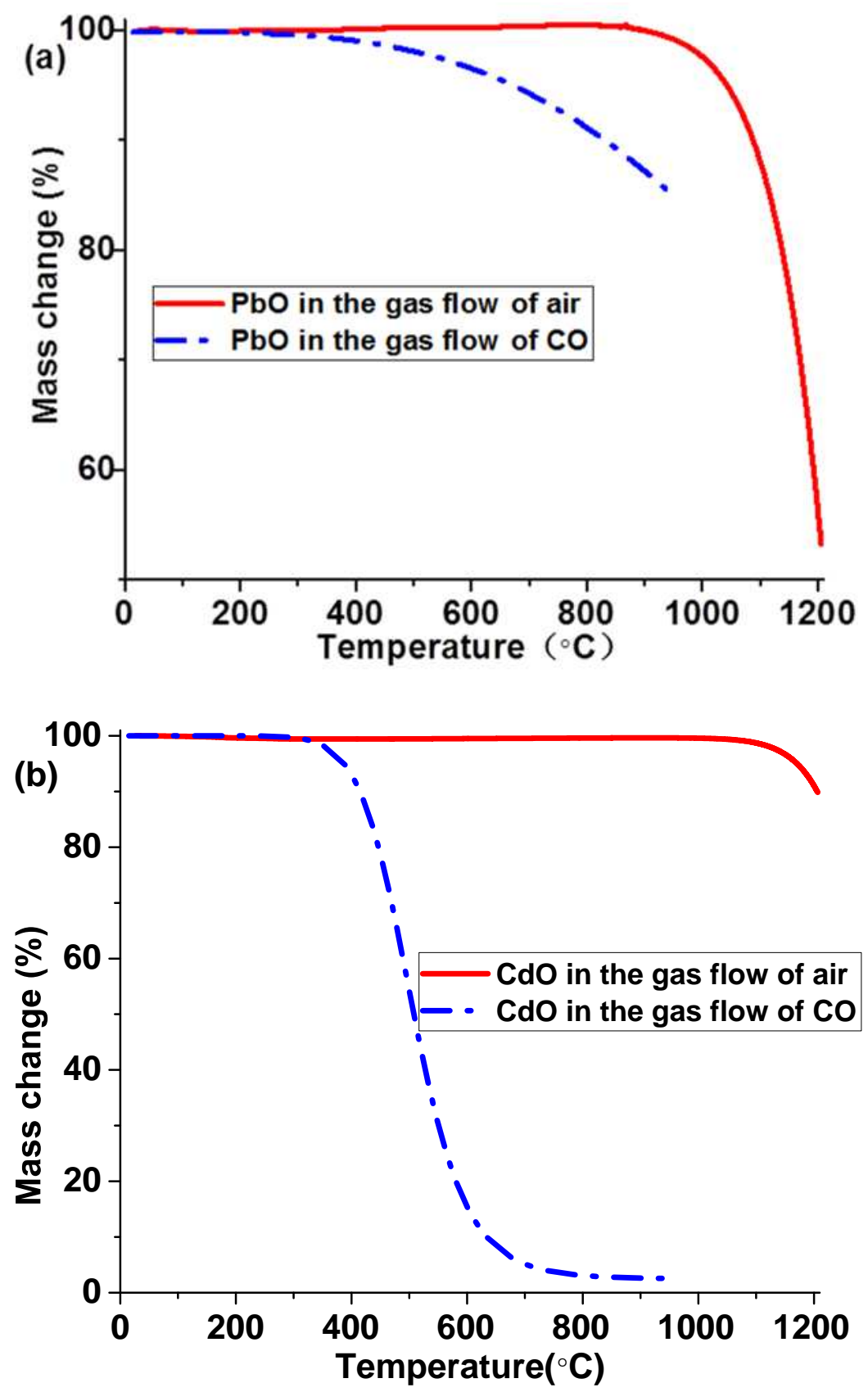

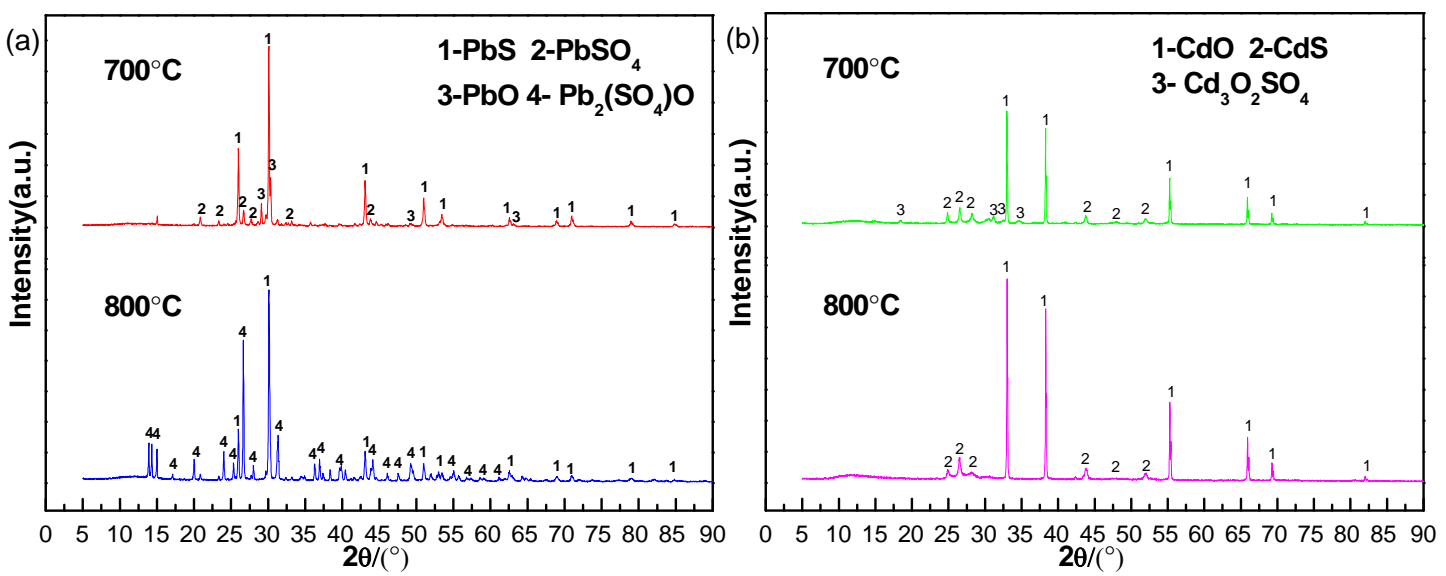

547
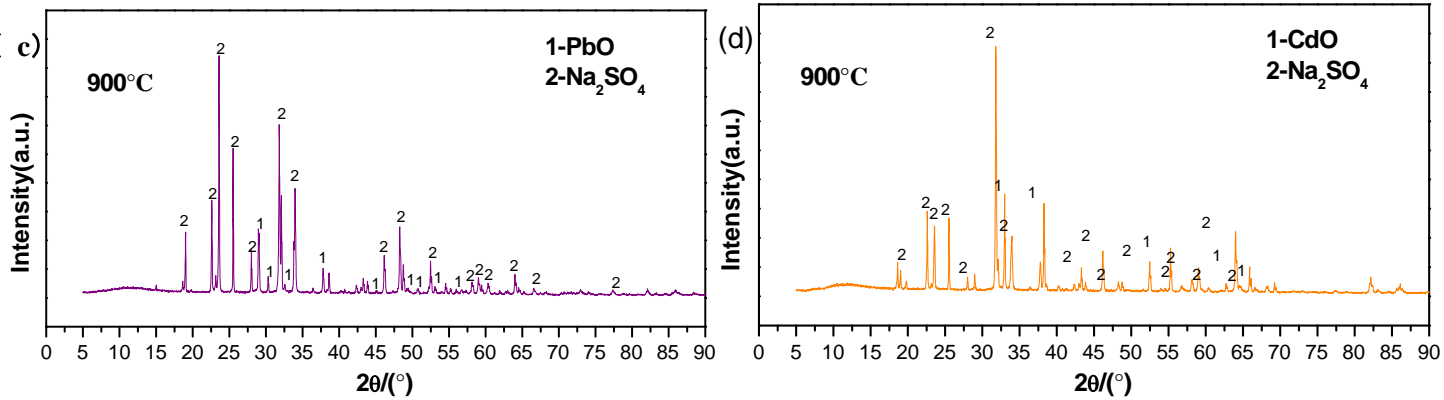

Fig. 6 XRD patterns of mixture of heavy metal oxides and sulfur compounds

(a) $\mathrm{PbO}+\mathrm{S}$, (b) $\mathrm{CdO}+\mathrm{S}$, (c) $\mathrm{PbO}+\mathrm{Na}_{2} \mathrm{SO}_{4}$, (d) $\mathrm{CdO}+\mathrm{Na}_{2} \mathrm{SO}_{4}$ 